\title{
Epidemiological changes in meningococcal meningitis in Niger from 2008 to 2011 and the impact of vaccination
}

\author{
Jean-Marc Collard ${ }^{1,7,8^{*}}$, Bassira Issaka ${ }^{1}$, Maman Zaneidou ${ }^{2}$, Stéphane Hugonnet ${ }^{3}$, Pierre Nicolas ${ }^{4}$, \\ Muhamed-Kheir Taha ${ }^{5}$, Brian Greenwood ${ }^{6}$ and Jean-François Jusot ${ }^{1}$
}

\begin{abstract}
Background: The epidemiology of bacterial meningitis in the African 'meningitis belt' changes periodically. In order to design an effective vaccination strategy, we have examined the epidemiological and microbiological patterns of bacterial meningitis, and especially that of meningococcal meningitis, in Niger during the period 2008-2011. During this period a mass vaccination campaign with the newly developed meningococcal A conjugate vaccine (MenAfriVac ${ }^{\oplus}$ ) was undertaken.

Method: Cerebrospinal fluid samples were collected from health facilities throughout Niger and analysed by culture, seroagglutination and/or speciation polymerase chain reaction, followed by genogrouping PCR for Neisseria meningitidis infections. A sample of strains were analysed by multi-locus sequence typing.

Results: N. meningitidis serogroup A cases were prevalent in 2008 and 2009 [98.6\% and 97.5\% of all N. meningitidis cases respectively]. The prevalence of serogroup A declined in 2010 [26.4\%], with the emergence of serogroup W Sequence Type (ST) 11 [72.2\% of cases], and the serogroup A meningococcus finally disappeared in 2011. The geographical distribution of cases N. meningitidis serogroups A and W within Niger is described.

Conclusion: The substantial decline of serogroup A cases that has been observed from 2010 onwards in Niger seems to be due to several factors including a major polysaccharide A/C vaccination campaign in 2009, the introduction of MenAfrivac ${ }^{\oplus}$ in 10 districts at risk in December 2010, the natural dynamics of meningococcal infection and the persistence of serogroup A sequence-type 7 for about 10 years. The emergence of serogroup W strains suggests that there may be a need for serogroup W containing vaccines in Niger in the coming years.
\end{abstract}

Keywords: Neisseria meningitidis serogroup A and W, Meningitis, Niger, Vaccination, MenAfriVac ${ }^{\oplus}$, Sequence-type lineage evolution, Immunization

\section{Background}

Neisseria meningitidis $(\mathrm{Nm})$ is responsible for frequent outbreaks of meningococcal meningitis in the African 'meningitis belt', a sub-Saharan zone which stretches from Ethiopia to Senegal. Epidemics show marked seasonality, peaking during the dry, hot season [1] and they can cause many deaths (mortality around 10\%) and residual disability. During major epidemics, attack rates can range from 100 to 800 per 100000 population.

\footnotetext{
* Correspondence: Jean-Marc.Collard@wiv-isp.be

${ }^{1}$ Centre de Recherche Médicale et Sanitaire, Niamey, Niger

7634 Boulevard de la Nation, YN034, PO Box 10887 Niamey, Niger

Full list of author information is available at the end of the article
}

Nm serogroup A (Nm A) is the main cause of epidemics in Africa. However, serogroup $\mathrm{C}$ was responsible for epidemics in Nigeria in the 1970s [2] and in Upper Volta (now Burkina Faso) in the 1980s [3], serogroup W sequence type (ST)-11 caused severe epidemics in Burkina Faso in 2002 and 2003 [4,5], and serogroup X caused an outbreak in Niger in 2006 [6]. A strategy of reactive immunization with an anti-meningococcal $\mathrm{A} / \mathrm{C}$ polysaccharide vaccine has been used for many years to control epidemics in the African meningitis belt, based on WHO recommendations [7]. This approach has mitigated the extent of meningitis outbreaks but it has not prevented the continuing occurrence of large outbreaks of the disease.

\section{Biomed Central}

(c) 2013 Collard et al.; licensee BioMed Central Ltd. This is an open access article distributed under the terms of the Creative Commons Attribution License (http://creativecommons.org/licenses/by/2.0), which permits unrestricted use, distribution, and reproduction in any medium, provided the original work is properly cited. 
The reactive vaccination strategy relies on early detection of outbreaks followed by mass vaccination with a polysaccharide vaccine adapted to the circulating serogroup, once an incidence threshold has been crossed. Polysaccharide vaccines provide only short-term protection in children and have little or no impact on pharyngeal carriage [8]. A newly developed meningococcal A conjugate vaccine, MenAfriVac ${ }^{\oplus}$, was introduced in 2010 in Burkina Faso, Mali and Niger through mass vaccination campaigns directed at those aged 1-29 years. Initial findings from Burkina Faso and Chad suggest that this vaccine provides some herd protection, by preventing pharyngeal carriage, as well as protecting directly vaccinated individuals $[9,10]$, as seen following the introduction of a monovalent meningococcal $\mathrm{C}$ conjugate vaccine in the United Kingdom [11]. The aim of the MenAfriVac ${ }^{\oplus}$ programme is to eliminate large meningitis outbreaks in the 26 most severely affected countries of sub-Saharan Africa.

The purpose of the study reported here was to study the circulation of $\mathrm{Nm} \mathrm{A}$ and Nm W in Niger since 2008, and to examine the current epidemiological situation in relation to the availability of polysaccharide vaccines against $\mathrm{Nm} \mathrm{W}$. We have also tried to correlate the marked decrease in the number of cases caused by $\mathrm{Nm}$ $\mathrm{A}$, and the increased number due to $\mathrm{Nm} \mathrm{W}$, with data on vaccination and to speculate on the evolution of sequence-type lineages and naturally acquired immunity in the study population.

\section{Methods}

\section{Ethics statement}

Cerebrospinal fluid (CSF) samples were collected from patients with suspected meningitis by clinicians, with the patient's or their family's oral consent, according to the national guidelines for routine clinical care in Niger. Aliquots of CSF remaining after routine CSF examination by health facilities for case management were sent on a voluntary basis to the Centre de Recherche Médicale et Sanitaire (CERMES) to meet the WHO guidelines of enhanced microbiological surveillance of meningitis. Confidentiality on patients' identity was guaranteed.

\section{Introduction of MenAfriVac ${ }^{\circledR}$}

MenAfriVac ${ }^{\oplus}$, a meningococcal A (MenA) tetanus toxoid conjugate vaccine, developed by the Meningitis Vaccine Project (MVP) (http://www.meningvax.org/), was introduced on a pilot scale in September 2010 in Niger (1 district). The first district to be vaccinated was Filingué, targeting 392,211 individuals aged 1-29 years (data from the Direction of Surveillance and Response to Epidemics (DSRE), Ministry of Public Health (MoPH), Niger). In December 2010, MenAfriVac ${ }^{\circledR}$ was introduced on a larger scale in Niger. Eight districts of the Tillabery and Niamey Regions, and 2 districts from the Dosso Region were vaccinated covering 3.1 millions of individuals. In 2011, Niger completed the last phase of their own vaccination campaigns (7.4 million individuals), boosting the total number vaccinated to almost 10.9 million.

\section{Epidemiological surveillance}

Epidemiological surveillance in Niger is undertaken by the Direction of Surveillance and Response to Epidemics (DSRE), MoPH. Quantitative data on incidence and the mortality per age class for all clinically suspected cases of meningitis who meet a standard case definition are notified weekly to the MoPH. This clinical surveillance is coupled to microbiological surveillance performed by CERMES using CSF samples collected throughout Niger.

\section{Collection of CSF}

In Niamey, between November and June (the meningitis season), aliquots of CSF kept at room temperature after routine CSF examination by national and regional hospitals for case management were collected by CERMES. Additionally, during the same period from 2003-2010, frozen CSF samples were collected monthly by CERMES from hospitals within a radius of $300 \mathrm{~km}$ from Niamey (Dosso and Tillabéry Regions). This collection was stopped at the time of the implementation of enhanced case by case surveillance in 2011. Refrigerated or frozen CSF samples, and occasionally CSF-inoculated transisolates (TI), were sent on a voluntary basis to CERMES or DSSRE by mandated transport companies from the rest of the country.

\section{Bacteriological and molecular analysis of CSF}

Laboratory confirmation of meningococcal meningitis was performed at CERMES using culture and/or PCR techniques on CSF or TI as described previously [12]. CERMES provided information weekly to the DSRE on the number of confirmed cases, their aetiology, sampling date and geographical distribution to aid decisions on epidemic control.

\section{Multi-locus sequence typing}

A representative sample of strains of $N$. meningitidis was sent every year from 2002 to the WHO collaborative centre (WHOCC) for the meningococcus in IMTSSA (Marseille, France) for multi-locus sequence typing (MLST). In 2011, strains were sent to the new WHOCC for the meningococcus at the Pasteur Institute, Paris, France. DNA-PCR-amplified fragments from seven housekeeping genes ( $a b c Z, a d k, a r o E, f u m C, g d h, p d h C$ and $p g m$ ) were sequenced and their allelic profiles compared to the existing alleles available on the Internet Multilocus sequence typing data bank (http://www.mlst. net) to determine their sequence type [13]. 


\section{Data management and analysis}

Descriptive statistics were used to describe the epidemiology of meningococcal meningitis using both data from epidemiological surveillance provided by the MoPH and from microbiological surveillance performed by CERMES.

\section{Results}

Surveillance data

From $1^{\text {st }}$ January 2008 to $31^{\text {st }}$ December 2011, the MoPH of the Republic of Niger reported a total of 22, 046 suspected cases of meningitis with a case fatality rate (CFR) of 5.7\% (Table 1, Figure 1). A major epidemic in 2009 accounted for $63.2 \%$ of the total cases but this outbreak had the lowest CFR (4.2\%). Microbiologic analyses of all CSF samples obtained during these four years are presented in Table 1 and shown on a weekly scale in Figure 2. In the 2008 and 2009 meningitis seasons, a large majority of meningococcal infections were due to $\mathrm{Nm} \mathrm{A} \mathrm{(98.6 \% ;}$ $\mathrm{N}=1067$ and $97.5 \% ; \mathrm{N}=1654$ respectively). $\mathrm{Nm} \mathrm{W}$ emerged in 2010 (72.2\% of isolates; $\mathrm{N}=665$ ) while the percentage of $\mathrm{Nm}$ A isolates declined (26.4\%; $\mathrm{N}=243$ ), and in 2011 there was a strong predominance of $\mathrm{Nm} \mathrm{W}$ isolates (98.1\%; $\mathrm{N}=402$ ) with only 5 isolates of $\mathrm{Nm} \mathrm{A}$. The increase in Nm W meningitis cases was accompanied by an increase in the CFR (from $6.7 \%$ and $4.2 \%$ respectively in 2008 and 2009 to $12.2 \%$ in 2011). Two of the five cases of $\mathrm{Nm} \mathrm{A}$ meningitis detected in 2011 in zones vaccinated with MenAfriVac ${ }^{\circ}$ concerned young males aged 12 and 25 years that had not been vaccinated. The other three cases came from districts where MenAfriVac ${ }^{\oplus}$ had not been distributed at that time that they became ill (Keita and Matameye in the central part of the country and Agadez in the north). Nm X cases were infrequent with only 22 PCR-positive CSF samples obtained over the four-year period, 15 of which were detected in 2009. Numbers of cases of Streptococcus pneumoniae meningitis remained relatively constant over the observation period with 117, 78, 93 and 70 cases respectively detected in 2008, 2009, 2010 and 2011 respectively. Pneumococcal conjugate vaccination will be introduced in Niger likely in 2015. Fifty-four percent $(\mathrm{N}=$ 5393) of CSF samples remained without a bacteriological aetiology after culture and PCR.

The mean ages of confirmed cases of serogroup A meningitis $(\mathrm{N}=2969)$, and serogroup $\mathrm{W}$ meningitis $(\mathrm{N}=$ $1078)$, were $10.3(\mathrm{SD}=7.8)$, and $8.9(\mathrm{SD}=10.3)$ years respectively $(\mathrm{t}$-test $=3.95, \mathrm{df}=1490, \mathrm{p}<0.0001)$. The age groups most affected were 5-9 years and 1-4 years for serogroups A and W respectively (Figure 3 ). The numbers of serogroups A and W confirmed cases in those less than 2 years were $84(2.97 \%)$ and $168(16.28 \%)$, respectively.

\section{MLST Molecular typing}

Most of the $\mathrm{Nm}$ A strains analysed $(\mathrm{N}=141)$ by MLST during the 2002-2011 period belonged to ST-7 $(\mathrm{N}=131$; 92.9\%) (Table 2), except for nine ST-2859 isolates (6 in 2007, 2 in 2008 and 1 in 2009) and one ST-5788 isolate (obtained in 2006). The strains belonging to ST-2859 all originated from Niamey, whereas the other ST-7 strains were isolated from all parts of the country. Nm W strains isolated in 2010 and $2011(\mathrm{~N}=30)$ and analysed by MLST belonged to ST-11. Nm W ST-11 strains were also isolated in $2002(\mathrm{~N}=4)$ and $2003(\mathrm{~N}=5)$. From 2004 to 2009 all Nm W strains analysed were ST-2881 $(\mathrm{N}=22)$.

\section{Geographical analyses}

A map of the Regions (or Departments) and Districts (or Arrondissements) of Niger can be accessed at http:// commons.wikimedia.org/wiki/Atlas_of_Niger. Figure 4 shows the geographic extension and decline of $\mathrm{Nm} \mathrm{A}$ in Niger between 2008 and 2011, and the extension of Nm W since 2010.

2008: $\mathrm{Nm}$ A cases, representing $98.6 \%$ of the total $\mathrm{Nm}$ cases, were concentrated in the southern and central

Table 1 Results from the epidemiological and microbiological surveillance of meningitis in Niger (2008-2011)

\begin{tabular}{|c|c|c|c|c|c|c|c|c|c|c|c|c|c|c|c|}
\hline Year & $\begin{array}{l}\text { Notified } \\
\text { cases }\end{array}$ & Deaths & CFR & $\begin{array}{l}\text { CSF } \\
\text { collected }\end{array}$ & $\begin{array}{l}\text { \% CSF } \\
\text { collected/ } \\
\text { declared } \\
\text { cases }\end{array}$ & $\begin{array}{l}\text { Nm } \\
\text { (all types) }\end{array}$ & $\mathrm{Nm} \mathrm{A}$ & $\mathrm{Nm} \mathrm{W}$ & $\mathrm{Nm} \mathrm{X}$ & $\begin{array}{l}\text { Other } \\
\text { serog. }\end{array}$ & $\begin{array}{l}\text { Non-typ. } \\
\text { Nm }\end{array}$ & Spn & $\mathrm{Hi}$ & Other & $\begin{array}{l}\text { Negative } \\
\text { CSF }\end{array}$ \\
\hline 2008 & 3851 & 256 & 6.65 & 2716 & 70.5 & 1082 & $\begin{array}{l}1067 \\
(98.6 \%)\end{array}$ & 0 & 5 & 0 & 10 & 117 & 33 & 23 & 1461 \\
\hline 2009 & 13943 & 589 & 4.22 & 3915 & 28.1 & 1696 & $\begin{array}{l}1654 \\
(97.5 \%)\end{array}$ & 11 & 15 & $1(Y)$ & 15 & 78 & 12 & 66 & 2063 \\
\hline 2010 & 2908 & 251 & 8.63 & 2384 & 82.0 & 921 & $\begin{array}{l}243 \\
(26.4 \%)\end{array}$ & $\begin{array}{l}665 \\
(72.2 \%)\end{array}$ & 1 & 0 & 12 & 93 & 22 & 26 & 1322 \\
\hline 2011 & 1344 & 164 & 12.20 & 1041 & 77.5 & 410 & 5 & $\begin{array}{l}402 \\
(98.1 \%)\end{array}$ & 1 & 0 & 2 & 70 & 2 & 12 & 547 \\
\hline Total & 22046 & 1260 & 5.71 & 10056 & 45.6 & 4109 & 2969 & 1078 & 22 & 1 & 39 & 358 & 69 & 127 & 5393 \\
\hline
\end{tabular}

Epidemiological data are from the Direction of Surveillance and Response to Epidemics (DSRE), Ministry of Public Health; Microbiological data from CERMES. CSF, cerebrospinal fluid; $\mathrm{Nm}$, Neisseria meningitidis, CFR, case fatality rate. 


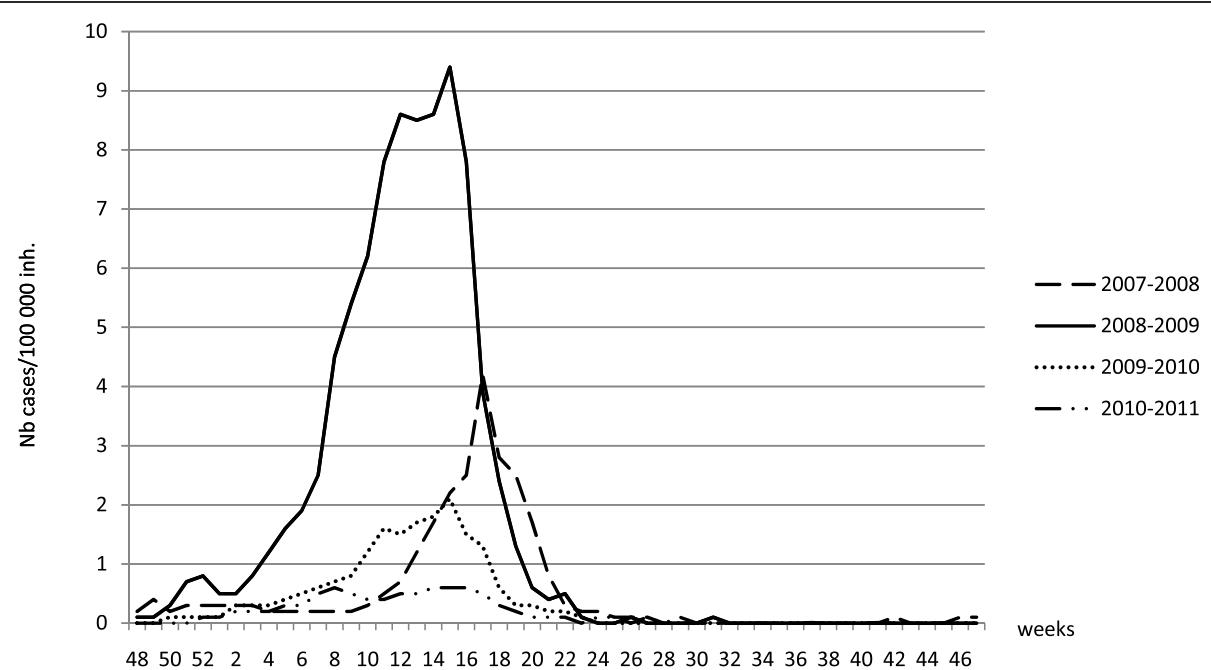

Figure 1 Attack rates of meningitis in Niger during the years 2008 to 2011 (data collected by the Direction of Surveillance and Response to Epidemics - Ministry of Public Health).

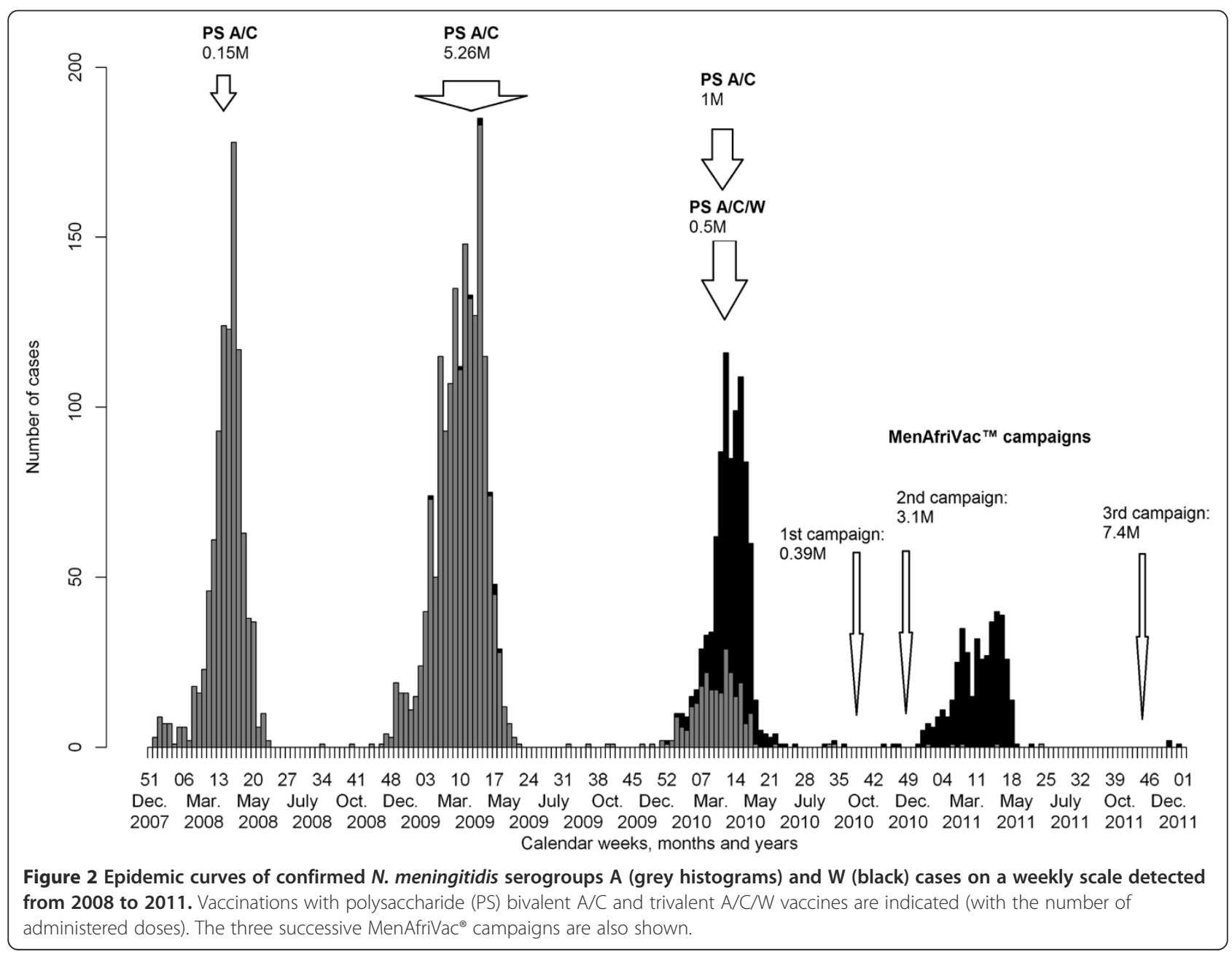




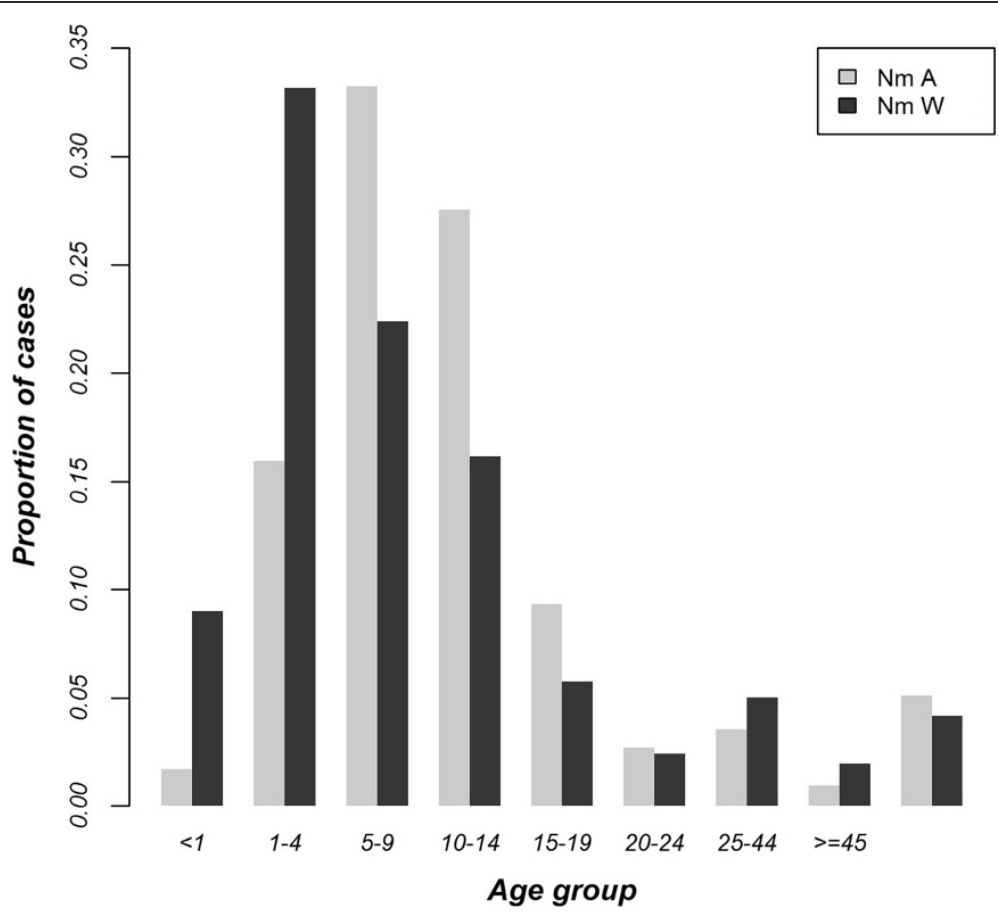

Figure 3 Age groups affected by N. meningitidis serogroups $A(N=2964)$ and W $(N=1077)$ from 2008 to 2011.

parts of the country (Dosso, Tahoua, Maradi and Zinder regions), along the border with Nigeria.

2009: Nm A cases dominated again (97.5\%) with very few cases of other serogroups (15 Nm X, $11 \mathrm{Nm} \mathrm{W,}$ $1 \mathrm{Nm} \mathrm{Y,} 15$ non groupable (NG)-Nm) being detected among 3915 CSF samples analyzed. Nm A cases were spread over almost the whole country. During the epidemic season twenty-five of the 42 health districts had an attack rate of suspected cases over 10/100,000/week (epidemic threshold) and 11 districts an attack rate over 5/100,000/week (alert threshold). During the epidemic peak, attacks rates reached values up to 33.4 and 27.6/ 100,000/week in Madarounfa and Magaria districts respectively.

2010: Nm A cases (26.4\% of all meningococci) were still distributed across almost all districts (32/42), but the number of confirmed cases had decreased remarkably $(\mathrm{N}=243)$ whereas $\mathrm{Nm}$ W cases increased dramatically in number $(\mathrm{N}=665$ cases; $72.2 \%)$ and were recorded in $35 / 42$ districts. Nm A cases were concentrated in the western part of the country whereas the highest numbers of Nm W cases were observed in the southern and central parts of the country (mainly in Maradi and Madarounfa districts). To investigate the geographical distribution of the mixed epidemics of 2010, the distribution of serogroups A and W by month by health centre catchment area (HCCA) was determined. Figure 5 showed that in January 2010, Nm W cases began to emerge in HCCA of three districts, two located at the borders with Nigeria and one located at the border with Burkina Faso. Nm A cases were detected in HCCA of 11 districts. In February, $\mathrm{Nm}$ A remained the predominant serogroup and cases were present in HCCA of 12 districts whereas $\mathrm{Nm} \mathrm{W}$ spread to HCCA of 9 districts located in the centre of Niger. In March, Nm W continued to be detected to the Western and Eastern region of Niger while $\mathrm{Nm} \mathrm{A}$ remained predominant in HCCA of 10 districts located in the Western part of the country. April 2010 showed a clear predominance of $\mathrm{Nm} \mathrm{W}$ in HCCA of 26 districts.

2011: Nm W cases (97.8\%) were recorded predominantly in the western and central parts of the country (except for the district of Matameye). About 50\% of the $\mathrm{Nm} \mathrm{W}$ cases originated from the region of Tillabery vaccinated with MenAfriVac ${ }^{\odot}$ in December 2010. No cases were reported from the eastern part of the country (Magaria, Zinder, Tanout, Mirriah, Maine Soroa, Nguigmi and Diffa districts) bordering Nigeria and Chad.

\section{Vaccination}

In 2008, in response to the epidemic, 146,854 doses of polysaccharide (PS) $\mathrm{A} / \mathrm{C}$ vaccine were administered in the districts of Filingue and Say, with coverage of $52.4 \%$ and $54.7 \%$ of the target population respectively.

In 2009, in response to the epidemic, but also to prevent outbreaks in some districts considered at risk, PS A/C vaccines were used to immunize a total of 5,904,978 subjects across the whole country with a vaccination coverage (mean per district) of $52.4 \% \pm 39 \%$ for the target 
Table 2 Evolution of meningococcal Sequence-type (ST) and Clonal Complexes (cc) of serogroups A and W from meningitis cases in Niger from 2002 to 2011

\begin{tabular}{|c|c|c|}
\hline Serogroup & Year & $S T$ \\
\hline \multirow[t]{9}{*}{ A } & 2002 & ST-7 $(N=11)(\operatorname{cc5})$ \\
\hline & 2003 & ST-7 $(N=22)(\operatorname{cc} 5)$ \\
\hline & 2004 & ST-7 $(N=13)(c c 5)$ \\
\hline & 2005 & ST-7 $(N=16)(c c 5)$ \\
\hline & 2006 & ST-7 $(\mathrm{N}=11)(\mathrm{cc} 5)$ and $\mathbf{S T}-\mathbf{5 7 8 8}(\mathrm{N}=1)(\mathrm{cc} 5)$ \\
\hline & $\begin{array}{l}2007 \\
\text { (Nov) }\end{array}$ & ST-7 $(\mathrm{N}=21)(\mathrm{cc} 5)$ and ST-2859 $(\mathrm{N}=6)(\mathrm{cc} 5)$ \\
\hline & 2008 & ST-7 $(\mathrm{N}=7)(\mathrm{cc} 5)$ and $\mathbf{S T - 2 8 5 9}(\mathrm{N}=2)(\mathrm{cc} 5)$ \\
\hline & 2009 & ST-7 $(\mathrm{N}=27)(\mathrm{cc} 5)$ and ST-2859 $(\mathrm{N}=1)(\mathrm{cc} 5)$ \\
\hline & 2010 & ST-7 $(N=3)(c c 5)$ \\
\hline \multirow[t]{10}{*}{ W } & 2002 & ST-11 $(N=4)(c c 11)$ \\
\hline & 2003 & $\begin{array}{l}\text { ST-2881 }(N=7)(c c 175) \text { and ST-11 }(N=5) \\
\left(\mathrm{Cc}^{11}\right)\end{array}$ \\
\hline & 2004 & ST-2881 (N = 4) (cc175) \\
\hline & 2005 & ST-2881 $(N=7)(c c 175)$ \\
\hline & 2006 & ST-2881 ( $N=2)(c c 175)$ \\
\hline & 2007 & - \\
\hline & 2008 & ST-2881 (N = 2) (cc175) \\
\hline & 2009 & - \\
\hline & 2010 & ST-11 $(N=13)(\mathrm{cc} 11)$ \\
\hline & 2011 & ST-11 $(N=17)(\operatorname{ccl1})$ \\
\hline
\end{tabular}

Data are from the WHO Collaborating Center on Meningococci at Institut de Médecine Tropicale du Service de Santé des Armées (IMTSSA), Marseille, France before 2011 and from the Pasteur Institute, Paris, France since 2011.

population (including non-vaccinated districts). Coverage in vaccinated districts varied between $14 \%$ and $134 \%$ (population estimated on the last demographic census performed in 2001 explains values $>100 \%$ ). The two regions the most at risk, Maradi and Zinder, had vaccination coverages of $64.2 \%$ and $80.4 \%$ respectively. However, other regions, such as Tahoua, were barely vaccinated (13.8\%) with great variations between districts.

In 2010, in response to the epidemic due to $\mathrm{Nm} \mathrm{W}$, 509,621 doses of the trivalent PS A/C/W vaccine were distributed in the districts of Agadez, Maradi, Madarounfa, Madaoua and Zinder with vaccination coverage varying between $50 \%$ and $110 \%$. An additional 1,062,577 doses of the PS A/C vaccine were administered, including 540,640 doses for the Tahoua region, increasing the general vaccination $\mathrm{Nm}$ A coverage of the region to $38 \%$. In addition to vaccination responses, preventive vaccination campaigns with the MenAfriVac ${ }^{\circ}$ vaccine were organized in 2010 and 2011 as explained in the Methods section (Figure 1).

\section{Discussion}

$\mathrm{Nm}$ A has been the most prevalent cause of meningococcal meningitis in Niger since the start of microbiological surveillance in 1981, except in 1997 and 2006 when serogroup X [6,14] predominated. Serogroup X cases have not reemerged in Niger although observed in large numbers in Burkina Faso in 2011 [15].

The incidence of $\mathrm{Nm}$ A declined in Niger during the year 2010, the strain being replaced gradually by $\mathrm{Nm} \mathrm{W}$, and meningococci of this serogroup almost disappeared in 2011 (only five cases). This decline took place despite the fact that only 11 of 42 districts had received the conjugated vaccine (corresponding to 9.9 million of a total of 15.2 million inhabitants or 3.1 million of the 6.3 million target population for vaccination) in 2010.

There are several potential reasons which could account for the disappearance of $\mathrm{Nm} \mathrm{A}$ from the whole country. The primary reason is likely to be the fact that meningococcal epidemics have a natural dynamic in the meningitis belt, as already described by Lapeyssonnie in 1963 [16], and there was a general decline in serogroup A colonization and disease in the meningitis belt prior to the introduction of the serogroup A conjugate vaccine in 2010 [15]. The persistence of Nm A Sequence-Type (ST)-7 for about 10 years in Niger (Table 2) may have contributed to the disappearance of the serogroup A meningococcus from the country around 2010 due to a build-up of natural immunity to this strain across the country during this period. Although the number of strains typed by MLST in our study was relatively low due to logistic constraints, and this could introduce a bias, we believe that our MLST results provide a reasonably representative picture of the different ST circulating during the epidemic seasons. Between 1995 and 1998, all $\mathrm{Nm}$ A isolates from Niger typed by MLST belonged to ST-5, from 1999 to 2001 to ST-7 (differing from ST-5 only at the pgm locus) [17], and from 2002 most of the isolates were ST-7 $[18,19]$. Serogoup A meningococci are largely clonal and all African isolates typed by the WHO Collaborating Centers for Reference and Research on Meningococci were remarkably homogeneous in their PorA (P1.20,9) and FetA (F3-1) sequences [20]. Hubert et al. also observed a remarkable antigenic stability of the PorA, PorB, and FetA proteins, but with occasional allelic exchange of opa genes, over years in $\mathrm{Nm}$ A isolates from Ghana and Burkina Faso [21]. According to Bart et al. [22], serogroup A meningococci do not persist in areas for more than a few years because they do not have the opportunity to accumulate genetic variants indefinitely and their survival mainly depends on geographic spread. Moreover, based on the time separating the ST-5 from the ST-7 outbreaks in Chad and Sudan, and the time taken for the spread of ST-5 from East Africa to Senegal and Guinea Bissau, Nicolas et al. [23] speculated that ST-7 might continue to spread until 2008 to 2009; our findings support this prediction. 


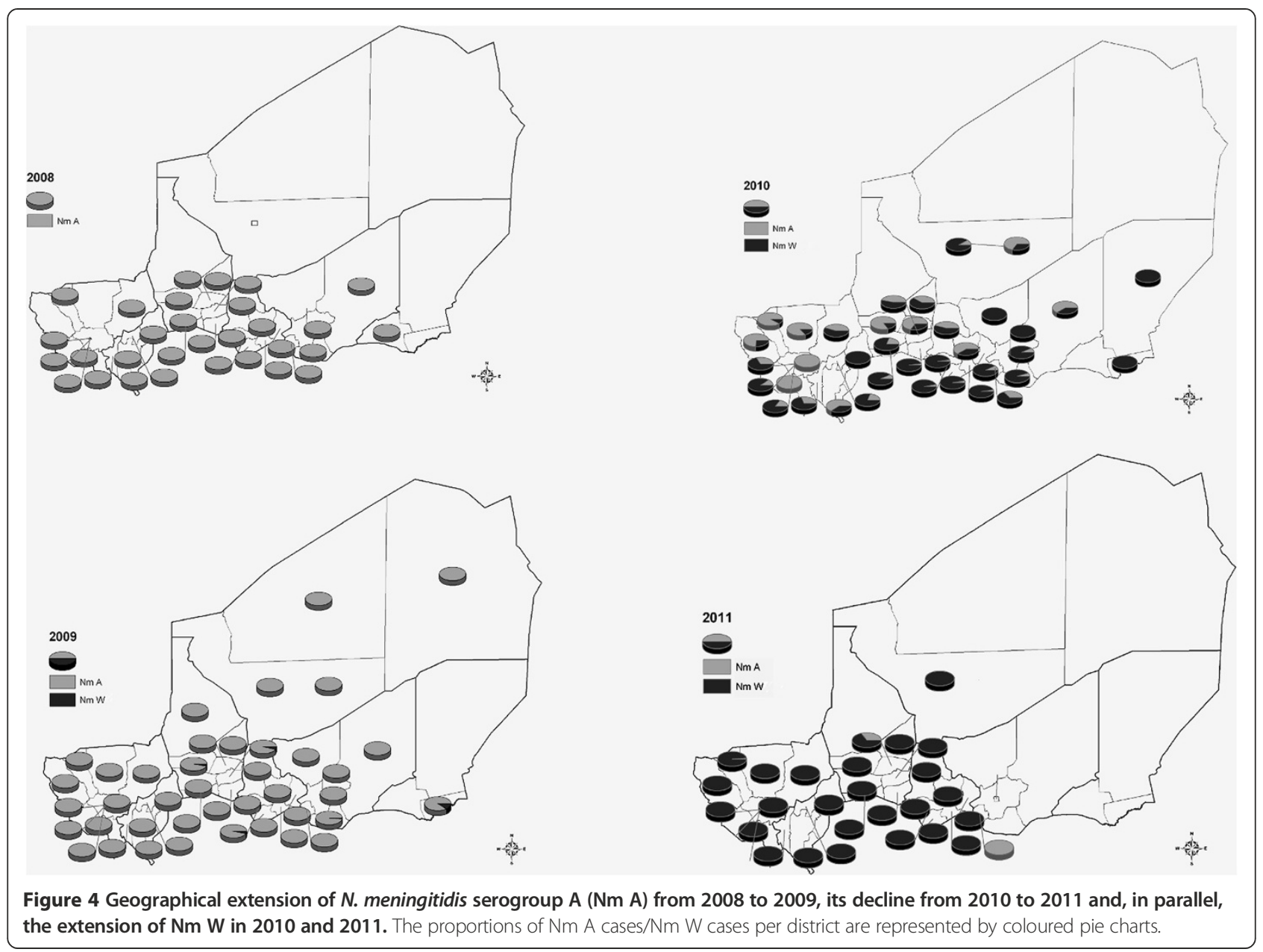

Another important factor contributing to the disappearance of serogroup A cases of meningitis from Niger may have been the massive vaccination of the population with the PS A/C vaccine during the previous three years, especially during the large outbreak in 2009. There is good evidence that PS meningococcal vaccines have little impact on carriage in the African meningitis belt $[24,25]$ and thus their widespread deployment is unlikely to prevent transmission or to reduce the reservoir of infection. However, high vaccine coverage rates will result in a marked reduction of cases among vaccinated people, even if some transmission of the epidemic strain continues within the population. This massive vaccination campaigns with the PS vaccine may have contributed to the drastic decrease of $\mathrm{Nm} \mathrm{A}$ cases but this is unlikely to be the only reason. Vaccination with MenAfrivac ${ }^{\circ}$, which began in December 2010 in the 11 districts of the Western part of Niger most affected by Nm A that year, may have helped to reduce the transmission of $\mathrm{Nm} \mathrm{A}$, at least in this part of the country and as found in Burkina Faso and Chad $[9,10]$.
Nm W has circulated in Africa for decades [26] but rarely caused outbreaks until the large epidemic in Burkina Faso in 2002 [27] caused by a sequence-type 11 serogroup W meningococcus, likely introduced by Hajj pilgrims returning in 2000 from Mecca and Madina (Saudi Arabia). In 2002-2003, molecular typing of the sporadic meningitis cases due to $\mathrm{Nm} \mathrm{W}$ in Niamey showed two STs, ST-11 and ST-2881, the latter a new ST differing at six of the seven MLST typing loci (Table 2) [18]. Between 2004 and 2008, all Nm W strains typed $(\mathrm{N}=15)$ belonged to the new ST-2881. Nm W strains of ST-11 have emerged again in Niger in 2010, causing a small epidemic ( $72.2 \%$ of all meningococci) [28]. As shown in Figure 5, the onset of epidemics due to Nm W strains started in the HCCA of three districts, two located at the borders with Nigeria and one located at the border with Burkina Faso, suggesting that $\mathrm{Nm} \mathrm{W}$ strains were already present in the population and widespread in Niger, making diffusion from a single point unlikely [29]. In 2011, all Nm W strains tested were ST11. ST-11 Clonal complex (cc)11 is known to be a hyperinvasive lineage which may replace the $\mathrm{Nm}$ A ST-7 


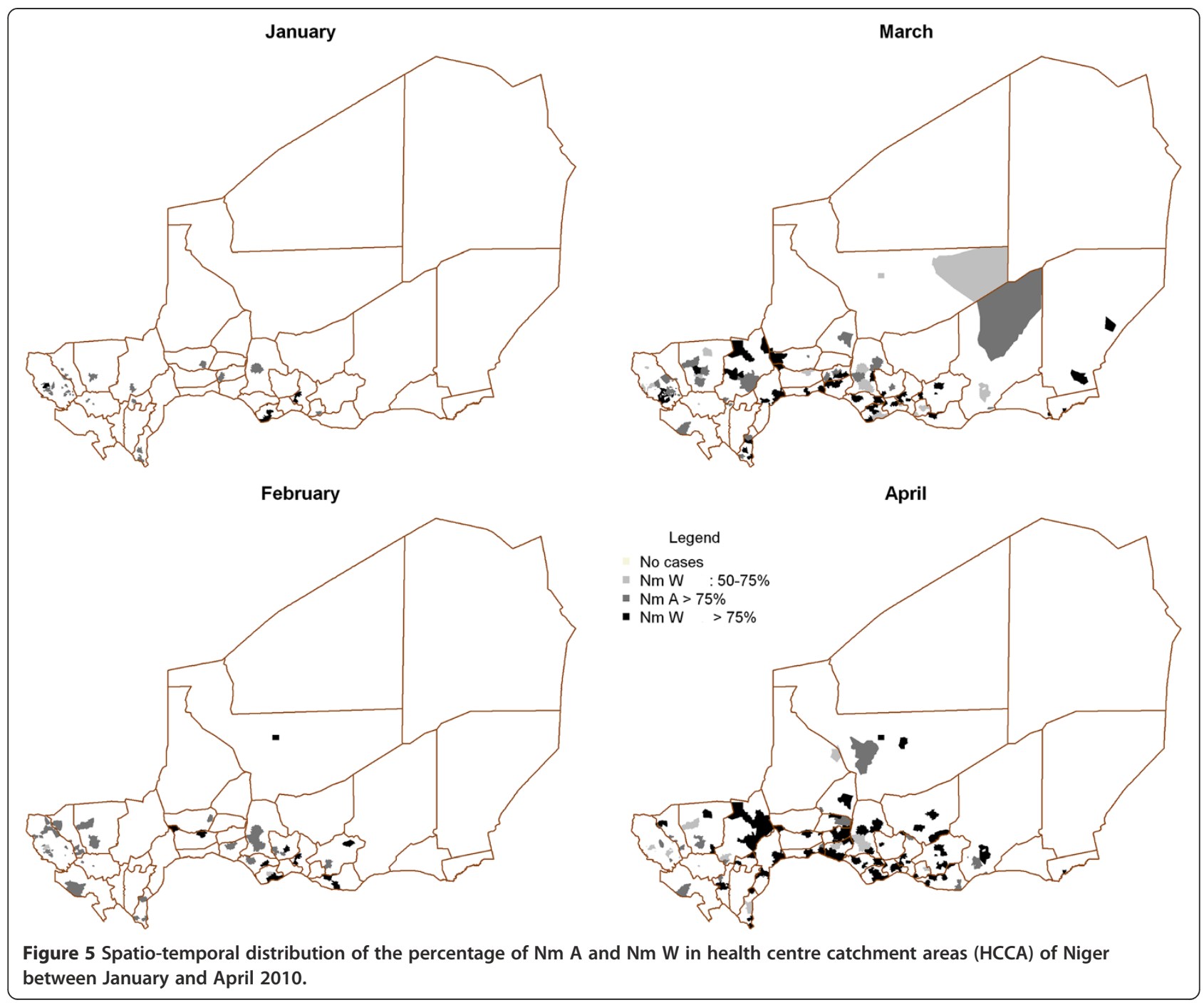

lineage since the country was entirely vaccinated with MenAfriVac $^{\circ}$ at the end of 2011. Further studies are needed to compare the recent $\mathrm{Nm} \mathrm{W}$ isolates belonging to cc11 and those of 2002-2003 in order to understand the reemergence of this Nm W strain.

We observed a significant difference in the age groups of patients infected with serogroup W or A, with the proportion of serogroup W infections being significantly higher among young children including those under two years of age, than among older subjects. Similarly, the attack rate during the meningitis serogroup $\mathrm{W}$ outbreak in Burkina Faso in 2002 was highest in patients $<5$ years of age and decreased with age [27]. These findings have implications regarding vaccination strategy. Currently, the reactive outbreak response strategy with either the PS $\mathrm{A} / \mathrm{C}$ vaccine or the $\mathrm{PS} \mathrm{A} / \mathrm{C} / \mathrm{W}$ vaccine is usually restricted to those aged 2-29 years because of concerns over the poor responsiveness of infants to polysaccharide vaccines. Use of conjugate vaccines, which are more immunogenic than polysaccharide vaccines in infants, in epidemic responses would allow the whole population to be vaccinated effectively.

\section{Conclusions}

Whereas large outbreaks of Nm A should be eliminated by widespread deployment of the conjugate A vaccine, it is not yet clear how the other serogroups, in particular W, will evolve in response to this new situation. This is an important reason for strengthening surveillance in order to detect and investigate outbreaks, to assess the dynamic of $\mathrm{Nm} \mathrm{W}$ outbreaks and to adapt the response strategy accordingly. Finally, it is also important to monitor the evolution and distribution of $\mathrm{Nm}$ of other serogroups in order to provide information on future vaccine needs. In the medium term, a new, affordable, multivalent (ACWXY) conjugate vaccine may be needed as the currently available quadrivalent meningococcal conjugate ACWY vaccines are too expensive for wide use in Africa. 


\section{Abbreviations}

CERMES: Centre de Recherche Médicale et Sanitaire; CSF: Cerebrospinal fluid; DSRE: Direction of Surveillance and Response to Epidemics; HCCA: Health centre catchment areas; MoPH: Ministry of public health; MLST: Multi-locus sequence typing; MVP: Meningitis Vaccine Project; PS: Polysaccharide vaccines; TI: Trans-Isolate medium; WHO: World Health Organization; WHOCC: WHO collaborative centre.

\section{Competing interests}

The authors have read the journal's policy and have the following conflicts. Funding was received from Sanofi Pasteur; however, there are no patents, products in development or marketed products to declare. This does not alter our adherence to all the BMC Infectious diseases' policies on sharing data and materials, as detailed online in the guide for authors. Stéphane Hugonnet is a staff member of the World Health Organization. The views expressed in this publication are those of the author alone and they do not necessarily represent the decisions, policy or views of the World Health Organization.

\section{Authors' contributions}

Analyzed the data: JMC JFJ ZM; Wrote the paper: JMC JFJ BG SH; Epidemiological surveillance and vaccine responses: ZM SH; Laboratory analyses coordinator: Bl; Molecular analyses: PN MKT; Map realization: JFJ. All authors read and approved the final manuscript.

\section{Acknowledgments}

This work was supported financially by the French Ministry of Foreign Affairs (FSP No. 2005-174) and by Sanofi Pasteur (contract Men07). The authors thank all the doctors and medical assistants who sent CSF/TI specimens and epidemiological forms to the CERMES, and also staff of the Direction de la Surveillance et de la Riposte aux Epidémies (DSRE), of WHO collaborating centers (WHOCC) and of the Division International of Pasteur Institue. We thank Issaka Seydou for his technical assistance during the 2011 epidemic and also Lagaré Adamou, Amadou Moussa, Sani Ousmane, Ali Sidiki and Djibir Zanguina for their technical support, Florian Girond for database management, and Saacou Djibo, Hamidou Amina Amidou and Jocelyne Rocourt for scientific and administrative interactions.

\section{Author details}

${ }^{1}$ Centre de Recherche Médicale et Sanitaire, Niamey, Niger. ${ }^{2}$ Direction de la Surveillance et de la Riposte aux Epidémies, Ministère de la Santé Publique, Niamey, Niger. ${ }^{3}$ World Health Organization, Geneva, Switzerland. ${ }^{4}$ WHO Collaborative Center for the meningococcus in IMTSSA (Institut de Médecine Tropicale du Service de Santé des Armées), Marseille, France. ${ }^{5}$ Institut Pasteur, WHO Collaborating Centre for Reference and Research on Meningococci, Paris, France. ${ }^{6}$ Faculty of Infectious and Tropical Diseases, London School of Hygiene and Tropical Medicine, London, UK. ${ }^{7} 634$ Boulevard de la Nation, YN034, PO Box 10887 Niamey, Niger. ${ }^{8}$ Current address: Scientific Institute of Public Health, Brussels, Belgium.

Received: 22 January 2013 Accepted: 4 December 2013 Published: 6 December 2013

\section{References}

1. Sultan B, Labadi K, Guégan JF, Janicot S: Climates drives the meningitis epidemics onset in West Africa. PLoS Med 2005, 2(1):43-49.

2. Whittle HC, Greenwood BM: Meningococcal meningitis in northern savanna of Africa. Trop Doct 1976, 6:99-104.

3. Broome CV, Rugh MA, Yada AA, Giat L, Giat H, Zeltner JM, Sanborn WR, Fraser DW: Epidemic group C meningococcal meningitis in Upper Volta, 1979. Bull World Health Organ 1983, 61(2):325-330.

4. Decosas J, Koama JB: Chronicle of an outbreak foretold: meningococcal meningitis W135 in Burkina Faso. Lancet Infect Dis 2002, 2(12):763-765.

5. Zombre S, Hacen MM, Ouango G, Sanou S, Adamou Y, Koumaré B, Kondé MK: The outbreak of meningitis due to Neisseria meningitidis W135 in 2003 in Burkina Faso and the national response: main lessons learnt. Vaccine 2007, 25(Suppl 1):A69-A71.

6. Boisier P, Nicolas P, Djibo S, Taha MK, Jeanne I, Maïnassara HB, Tenebray B, Kairo KK, Giorgini D, Chanteau S: Meningococcal meningitis: unprecedented incidence of serogroup X-related cases in 2006 in Niger. Clin Infect Dis 2007, 44(5):657-663.
7. World Health Organization: Detecting meningococcal meningitis epidemics in highly-endemic African countries. Wkly Epidemiol Rec 2000, 75(38):305-312.

8. LaForce MF, Ravenscroft N, Djingarey M, Viviani S: Epidemic meningitis due to Group A Neisseria meningitidis in the African meningitis belt: A persistent problem with an imminent solution. Vaccine 2009, 27(Suppl 2):B13-B19.

9. Kristiansen PA, Diomandé F, Ba AK, Sanou I, Ouédraogo AS, Ouédraogo R, Sangaré L, Kandolo D, Aké F, Saga IM, Clark TA, Misegades L, Martin SW, Thomas JD, Tiendrebeogo SR, Hassan-King M, Djingarey MH, Messonnier NE, Préziosi MP, Laforce FM, Caugant DA: Impact of the serogroup A meningococcal conjugate vaccine, MenAfriVac, on carriage and herd immunity. Clin Infect Dis 2013, 56(3):354-363.

10. Daugla D, Gami J, Gamougam K, Naibei N, Mbainadji L, Narbé M, Toralta J, Kodbesse B, Ngadoua C, Coldiron M, Fermon F, Page AL, Djingarey M, Hugonnet S, Harrison O, Rebbetts L, Tekletsion Y, Watkins E, Hill D, Caugant D, Chandramohan D, Hassan-King M, Manigart O, Nascimento M, Woukeu A Trotter C, Stuart J, Maiden M, Greenwood B: Effect of a serogroup A meningococcal conjugate vaccine (PsA-TT) on serogroup A meningococcal meningitis and carriage in Chad: a community trial. Lancet 2013, 6736(13):61612-61618

11. Campbell H, Borrow R, Salisbury D, Miller E: Meningococcal C conjugate vaccine: the experience in England and Wales. Vaccine 2009, 27(Suppl 2):B20-B29.

12. Chanteau S, Sidikou F, Djibo S, Moussa A, Mindadou H, Boisier P: Scaling up of PCR-based surveillance of bacterial meningitis in the African meningitis belt: indisputable benefits of multiplex PCR assay in Niger. Trans $R$ Soc Trop Med Hyg 2006, 100(7):677-680.

13. Maiden MC, Bygraves JA, Feil E, Morelli G, Russell JE, Urwin R, Zhang Q, Zhou J, Zurth K, Caugant DA, Feavers IM, Achtman M, Spratt BG: Multilocus sequence typing: a portable approach to the identification of clones within populations of pathogenic microorganisms. Proc Natl Acad Sci U S A 1998, 95(6):3140-3145.

14. Djibo S, Nicolas P, Alonso JM, Djibo A, Couret D, Riou JY, Chippaux JP: Outbreaks of serogroup X meningococcal meningitis in Niger 19952000. Trop Med Int Health 2003, 8(12):1118-1123.

15. World Health Organization: Inter country Support Team - West Africa Weekly feedback bulletin on cerebrospinal meningitis. Epidemiological situation of week 35 -39; From 29 August to $1^{\text {st }}$ October 2011. [http://www. who.int/csr/disease/meningococcal/BulletinMeningite2011_S35_39.pdf]

16. Lapeyssonnie L: La méningite cérébro-spinale en Afrique. Bull World Health Organ 1963, 28(Suppl):1-114

17. Nicolas P, Décousset $L$, Riglet V, Castelli P, Stor R, Blanchet G: Multilocus sequence typing of serogroup A meningococci isolated in Africa between 1988 and 1999 shows the clonal expansion of ST-5 and emergence of ST-7. Emerg Infect Dis 2001, 7(5):849-854.

18. Nicolas P, Djibo S, Moussa A, Tenebray B, Boisier P, Chanteau S: Molecular epidemiology of meningococci isolated in Niger in 2003 shows serogroup A sequence type (ST)-7 and serogroup W135 ST-11 and T-2881 strains. J Clin Microbiol 2005, 43(3):1437-1438.

19. Collard JM, Maman Z, Abani A, Mainasara HB, Djibo S, Yacouba H, Maitournam R, Sidikou F, Nicolas P, Rocourt J, Jusot JF: Microbiological and epidemiological investigation of the Neisseria meningitidis serogroup A epidemic in Niger in 2009: last wave before the introduction of the serogroup A meningococcal conjugate vaccine? Epidemiol Infect 2011, 139(11):1656-1660.

20. Caugant DA, Kristiansen PA, Wang X, Mayer LW, Taha MK, Ouédraogo R, Kandolo D, Bougoudogo F, Sow S, Bonte L: Molecular characterization of invasive meningococcal isolates from countries in the African meningitis belt before introduction of a serogroup A conjugate vaccine. PLOS One 2012, 7(9):e46019.

21. Huber CA, Pflüger $V$, Hamid AW, Forgor AA, Hodgson A, Sié A, Junghanss $T$, Pluschke G: Lack of antigenic diversification of major outer membrane proteins during clonal waves of Neisseria meningitidis serogroup A colonization and disease. FEMS Immunol Med Microbiol 2012. doi:10.1111/ 1574-695X.12000.

22. Bart A, Barnabé C, Achtman M, Dankert J, van der Ende A, Tibayrenc M: The population structure of Neisseria meningitidis serogroup A fits the predictions for clonality. Infect Genet Evol 2001, 1(2):117-122.

23. Nicolas P, Norheim G, Garnotel E, Djibo S, Caugant DA: Molecular epidemiology of Neisseria meningitidis isolated in the African meningitis 
belt between 1988 and 2003 shows dominance of sequence type 5

(ST-5) and ST-11 complexes. J Clin Microbiol 2005, 43(10):5129-5135.

24. Dellicour S, Greenwood B: Impact of meningococcal vaccination on pharyngeal carriage of meningococci. Trop Med Int Health 2007,

12(12):1409-1421.

25. Hassan-King MKA, Wall RA, Greenwood BM: Meningococcal carriage, meningococcal disease and vaccination. J Infect 1988, 16(1):55-59.

26. Kwara A, Adegbola RA, Corrah PT, Weber M, Achtman M, Morelli G, Caugant DA, Greewood BM: Meningitis caused by a serogroup W135 clone of the ET-37 complex of Neisseria meningitidis in west Africa. Trop Med Int Health 1998, 3:742-746.

27. Nathan $N$, Rose AM, Legros D, Tiendrebeogo SR, Bachy C, Bjørløw E, Firmenich P, Guerin PJ, Caugant DA: Meningitis serogroup W135 outbreak, Burkina Faso, 2002. Emerg Infect Dis 2007, 13(6):920-923.

28. Collard JM, Maman Z, Yacouba H, Djibo S, Nicolas P, Jusot JF, Rocourt J, Maitournam R: Increase in Neisseria meningitidis serogroup W135, Niger, 2010. Emerg Infect Dis 2010, 16(9):1496-1498

29. Paireau J, Girond F, Collard JM, Maïnassara HB, Jusot JF: Analysing spatiotemporal clustering of meningococcal meningitis outbreaks in Niger reveals opportunities for improved disease control. PLoS Negl Trop Dis 2012, 6(3):e1577.

doi:10.1186/1471-2334-13-576

Cite this article as: Collard et al:: Epidemiological changes in

meningococcal meningitis in Niger from 2008 to 2011 and the impact of vaccination. BMC Infectious Diseases 2013 13:576.

\section{Submit your next manuscript to BioMed Central and take full advantage of:}

- Convenient online submission

- Thorough peer review

- No space constraints or color figure charges

- Immediate publication on acceptance

- Inclusion in PubMed, CAS, Scopus and Google Scholar

- Research which is freely available for redistribution 